\title{
PLURALISMO CRÍTICO Y RECEPCIÓN LITERARIA
}

\author{
Jarío Villanueva \\ Universiclad de Santiago de Composicla
}

Se la convenido en que desde principios de los años setenta el modelo o paradigma esIructuralista que predominaba hasta entonces no sólo en nuestros estudios sino también en los propiamente lingüísticos hiso crisis, lo que dio paso al posestrucmalismo en el que nos encontrariamos en la actualidat. No se trata, como la propia denominación da a entender. de una rupturat radical, sin solución de continuidad, si tal cosal fuese posible en el terreno científico, (juc no lo es. El conocido físico Stephen Hawking recordaba no hace mucho cómo los lísicos actuales, hijos de la relatividad y la tcoría cuántica, no (lejan de explicar (leteminados aspectos de su disciplina de acuerdo con la mecánica newtoniana, pucs les resulta rentable por su mayor simplicidad e inteligibilidad pese a la evidencia de su superación (1989, 29). Por ello se ha llegado a afirmar (pue los posestructuralistas son los estructuralistas fue de pronto se dan cuenta (le su error. Fiste enfoque no es ajeno al que yo mismo quisiera dar a estas páginas, si dejo bien sentado descle un principio que el error al que se alude lo es tan solo parcial. Parto, pues, de la convicción de (pue el conocimiento cientílico prospera, como sostiene Popper (196.3, 13) "a lavés de anlicipaciones injustificadals (e injustificables), de presunciones, de soluciones tentativas para mestros problemas, de conjertmras. Estas conjetulas son controladas por la crítica; csto es, por intentos de refulaciones entre las que se encuentran tests severamente crílicos. Fillas pueden sobrevivir a estos tesls, pero nunca pueden ser justificadals categóricamente: no se las puede establecer como indudablemente verdaderals, ni tan siquiera cono 'probables'». porque como argumentará el filósofo de la ciencia vienés en su obra de 1972 Objective Knowledge (1972, 67-7.5). el propósito de la Ciencia no es el logro absoluto de la verdad, sino una aproximación escalonada a ella a través de sucesivas propuestas regidas por el criterio sustitutivo de la verosimilitud y sujetas al cumplimiento escrupuloso de los taes repuisitos de autoconsecuencia, exhaustividad y simplicidad constituti- 
vos del Ilamado primcipio empririco (pue Hjelmslev proponía como exigencia inexcusable para toda investigatión rigurosa ell sus Prolegémenos a una leoria del lengunje (1969. 22-23). Existe, pues, en el seno del pensamiento científico contemporáneo, un principio de sano relativismo difícilmente rechazable, y baste remitimos para campos que no son el nuestro al cjemplo ya citado de Newton y Finstein. Una determinada teoría o sistena posee, de hecho, un grado de corroboración, de certezal y operatividad más elevado o menor que otra hasta un momento (ado, pues todo aumento de conocimiento consiste en el perfeccionamiento del conocer yal existente que se modifica con vistiss a una mayor aproximación a la verdad.

Fin relación a los mélodos y escuelas teórico-críticas, forzoso es admitir que en el periodo comprendido entre el principio (lel siglo y mediados los años sesenta lo que ha predominado han sido las posturas exclusivistas. Como índice de ello baste recordar el immanentismo a ultranra de la escuela formalista rusa, y alguna de sus homólogas no cslavas, la envidiable seguridad en sí mismos de que algunos semióticos lacían gala al reconocerse como los úni$\cos$ que practicaban una auténtica Ciencia literaria pese a que contonces su Semiótical cra —como lambién la Retórica una disciplinal «restringidal», «ampulada», por sus carcncias en el clesarrollo de la pragmática, cuando no conducía a aguel exceso la aplicación a la literatura de sistemas cerrados, omnicomprensivos de la realidad social y humana como el marxismo o el psicoanálisis.

Mas en los áltimos lustros los vientos parecen haber cambiade de rmmbo, y hoy, en pleno post-estructuralismo, predomina la actitud comtraria, resumida en una palabra que Wayne C. Bootlo. uno de los más destacados representantes del círculo de (hicago, consagraba en el título de su libro (iritical Understanding. The Porrers and limits of Pluralism (1979). Fise pluablismo es lo que Paul K. Feyerabend (1986) denomina proliferación -la necesidaal de trabajar no con una sola teoría, paradigma o sistema de pensamiento, sino con varios desde el comienzo de nuestras investigaciones, concepto que junto a la critice y la realidad constituyen según él las tres ideas básicas en el desarrollo de la historia de la ciencia, la lïlosofía y la civilación misma.

Del citado Wayne C: Booth me interesa también su arlículo del número nonográlico de la prestigiosa revista Critical Inenuiry $(12,1986)$ dedicado a este tema en 1986, pues allí Booth lo relaciona con la práctica docente: "Pluralism in Classroom».

Este énfasis pedagógico no ha estado ausente de los horizontes que se matraron algunas de las escuelas más influyentes de toda la Ciencia literaria contemporánea, y sería incurrir en obviedacl mencionar a este respecto el antecedente de la Retórica. Así ocurre, singularmente, con la Estilística de Spitzer y de los grandes maestros españoles, pero también, y de forma no menos apreciable, en el New Criticism y en la propia escuela de Chicago a la que Booth pertenece. 'Títulos como An Approach o literature (1936) de Brooks, Warren y Pursuer, Understanding Fiction (1943) de los dos primeros, y Understanding Drama (194.5) del propio Brooks y Heilman dan buena fe de lo que digo. Y como los nuevos tiempos no sólo no han desaconsejado tal estratcgia sino que parecen, a lo que creo, reclamarla cadla ve\% con mayor intensidad -- véase sino cómo Jonathan Culler dedica todo un capítulo de uno de sus últimos libros, The Pursuit of Signs (1981) al tema de la Teoría literaria en los programas graduildos-, no dejaré de expresalr desde ahora mismo mi convencimiento de que nuestra tarea prioritaria es la de contribuir a través de la docencia y la investigación al anudamiento de esa cadena que, tanto desde la Teoría literaria y la Crítica de obras concretas en ella fundantentada como desde la comparación de las diferentes literaturas, debe extenderse hasta la didáctica de las mismas. Y ello en los términos a la vez más rigurosos e inteligibles, para que esta úl- 


\section{PI.URALISMO (:RÍTICO Y RI:CLPCIÓN LITLERARIA}

tima actuación sobre los textos resulte eficazmente fecundada por los nucvos hallazges de las pesquisals teóricas de más altos vuelos. Li momento es, por otra parle, especialmente delicado a estos efectos, pues estamos asistiendo a mal reforma de los planes de estudio de las Universidades españolas en la que la Teoría literaria va a desempeñar un papel destacado en los primeros ciclos de todas las filologías y se reconoce por primera vez la licenciatura de Teoría de la l.iteratura y Literatura comparada.

Pero volvamos al artículo de 1986 publicado en Ciritical lncluiry. Contiesa allí Bosth que descle la cátedra utiliza un "unsystematic procedure» que puede denominarse uaddling monism». liste «monismo acumulativo» consiste en presentar y articular una plumalidad de perspectivals que provocuen en los estudiantes una reacción tendente a reemplazar su «intuitive relativism or dogmatic monism» por un pluralismo activo y ejemplar (Booth, 1986. pp). 472-73). Con ello se pretende destruir esal especie de "estructura de poder» segúm la cual lo que el propio Booth u otro crítico o profesor de Literatura dice sobre una obra literaria precondicionat hastia su anulación lat experiencia del encuentro del estudiante con ella. Y todo por un designio superior de voluntad humanista en el seno de una sociedad gue favorece la uniformiclad acrítica: "Humanistic study is precisely the kind that places the richness of particular achievements at the center: It is the particularity of particulars that we find most villuable in the human works that come our way's (Booth, 1986, p. 474).

Doblemente signilicativo, por provenir (le nuestro propio ámbito intelectual, me parece el testimonio. coincidente con el de Booth, que Antonio (iarcía Berrio aportaba en un epílogo rotulado también de forma harto expresival, "Mals allá de los 'ismos': sobre la imprescindlible globalictad crílical» (Aullón de Haro, compilaclor, 1984, 349-387), cinco años antes de su Teoría de la literanura (l.a construeción del significade poético) (1989), magna obra en gran parte centrada en la discusión son sus propias palabras de los "clatos y síntomals muy heterogéneos del relativismo crítico y teórico, cue se potenció con la crisis de la Poétical cstructuralista hace (lie\% o quince años" (p. 9) y eni la que creos percibir un cambio de actitud por parte de su autor ante la realidad posestructuralista de la que estamos tratando.

Fin efecto, en apuel epílogo de 1984 García Berrio no ocultala su evolución descle el rotunclo inmanentismo linguístico y textual gue lo caracterizalla, denunciando entonces un "níti(lo proceso de agotamiento de los ismos». acaso debido a "los desarrollos aberantes de las demasías metodológicas». Continuar sometiéndose a su tiranía sería únicamente reflejo, según palabras de (iarcía Berrio a las que quisiera modestameme sumarme, de euna pura y simple lacha de limitación e impotencia, y un de texlo lo contrarion, frente a la cue él nos presenta la posibilidad ideal de ehacer entrar en colaboración el mayer número pesible de modelos parafrasísticos del texto objeto, servido desde todals las experiencials y disciplinals razonablemente conexas con la serie literaria» (p. 366), muy en la línea - me permito subrayar por mi parte - de aquella prostiferación demandadia por Feyerabend.

Resulta en especial sumamente ilustratival la declaración que García Berrio hace de la autonomía disciplinar de la Crítica en relación con la Lingüística, de la «naturalèa de mediación o Iectura interpuesta» que aquella tiene (p. 358) y de la urgencia de complementar el innanentismo formalista con consideraciones sociológico-ideológicas. Abrir, en una palabra, el texto a su contexto. Io que hace tan solo unos lustros sería recharato como lesa traiciói a las esencias (lel objeto literario. Fl propio García Berrio $(1978,52)$ había yal adelantado su postura de 1984 al afirmar que se sentía intermediario entre la linguística y la llistoria de la literatura, y entre las gramáticas formales típicas del estructuralismo y las deducciones socio- 


\section{I)ARÍ() VILL.ANUEVA}

lógicas de las obras literartias, al tiempo que reivindicaba la fïlología en su «condición olvidacla de gran ciencia de los iextoss.

Lin una dirección coincidente hay yue reseñar la notable apertura de la Semiótica literaria a consideraciones contextuales. propiciada por el acusado desarrollo (ue en su paradigma metodológico viene experimentande úllimamente la Pragmáticá por la que el discurso semiólico se pone en relación con el que lo ha producido y sus destinatarios, con las coordenadas de espacio y tiempo yue los condicionan, con otras series literarias o artísticals en general o con la propia historia y ba cvolución social según propone Jontathan Culler (1981, 214) en el citado capítulo de su libro The Pursuit of Signs tilulaclo "l iterary Theory in the Graduate Program!n.

Por los años en que (iarcía Berrio inciaba la evolución ya comentadlat, e incluso un poco antes, Marría del Carmen Bobes Naves presentabal la obra de W. O. Hendricks (I9)76, 7 21) Semiologín del discurson literarion identificando lat crítica semiológica con una tradición integradora en la (que tenían calbicla el formalismoseruso, la semiólical filosófica y la linguística estructural, y describiendo su método ucomo un conjunto de presupuestos más o menos generales, de posibilidades teóricas. de modelos explicativos entre los yue el investigador puede clegir el más adecuado (en conjunto o en paltes delerminadas) para el texto cue analice, o para el aspecto que quiere conocer». No mucho antes ella misma había delendiclo en su lectura semiológical de ('ámtico) (Bobes, 197.5, 2.50) la legitimidad de cualepuier esquema analítico si aplicado coherentemente y conforme al las peculiaridades del texio cuyo estudio se pretende.

Mientras que a finales de los sesenta la I.ingiístical del texto se difundía desde las Universidades alemanas de (onstamya y Bielefeld (con el concurso posterior, y ciertamente decisivo, (lel holandés Teun A. van Dijk), hoy por hoy ambas se distinguen por ser los loces directrices de la Fesética de la recepción y la Teoría empírica de la l iteratura. respectivannente. Y cuando uno de los máximos exponentes de esta líltima. Siegfried J. Schmidi, parece expresall un límielo despego hacia la integración de métodos de la que hablábamos, el tradluctor y

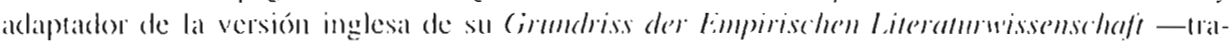
ducido en una colección que yo dirijo por Piancisco (hicos Rico, con el lítulo de fiundementlos de la ciencia empirica de la literenture $(199)$. Robert de Beaugrande. Ie sale al paso con la siguiente nota: "I am less inclined than Prof. Schmidl to view this pluralism als a sign of crisis. It might simply eflect the need for multiple models to capture the rich interpretative potential of important works of literatures (S. J. Schmidt. 1980), 170, n. 9).

Precisamente en el mismo número de Critical mequiry donde aparecía el articulo de Booll antes glosialo, Ihab Hassan formula una hipótesis realmente alractival la de (ue el pluralismo imperante en la actual (iencia literaria es resultado de las deteminantes sociales, inrelectuales, estéticas y filosóliciss del thamado postmodernismo. Y aduce en su defensa ma cadena de característicals posmodernas no ajenas a nuestra realidad. Entre ellas destaca, como no poelía ser menos, la de la fragmennación. entendida a la luz de Jean François l,yotard como el rechazo de la racionalielad botalizante, el descrédito de los glandes relatos legitimaldores, la acephación despreocupada de la pluralidad. De la misma fuente procede la descermonizariom. esa actitud iconoclastal que permite lanto deconstruir los lenguajes como halblar de "la muerte (le Lios". "la muerte del padre" o, por lo que a nosolros respecta, "la muerte del autor». Pero acaso el rasgo más moderno y más interesante descle nuestro punto de vista sea el que Ihab Hassan concreta en la indeterminación que ejemplifical en Werner Karl Heisenberg, en la noción de la incompletitud de Kurt (iödel, en los paradigmas de Thomas Kuhn y 
ef principio (el error fundamental para la teoría anarequista del conocimiento de Palul feyerabend, pero también con la «imlaginación dialógica» de Bajtrin. los lugares de indeteminación de Wolfgang Iser, las «lecturas crradas» de I larold Bloom o las «allegorical readings"s de Paul de Mann, la estilístical afectiva de Stanley Fïsh, el análisis transaccional de Norman Holland o el «subjective criticism» de David Bleich. Mas no quisiera dejall detinitivamente este sugestivo trabajo de llassan sin asumir como mía otra conclusión del mismo, amén de la de que el pluralismo crítico está hondiamente emmazade en la cultura de la posmodernidad. Me refiero al que "a limited critical pluralism is in sone measure a reaction against the radical relativism, the ironic incletermanences, of the postmodern condition; it is an attempl to contain theml” (Ilassan, 1986. 508).

Puede hablarse, en efecto, de la absoluta receptividad con que tanto en Europa como co América ha side acogida esta posición pluralista. Uno de los docunentos más interesintes e ilustratives de la situación en que se encontraba la Ciencia literaria en el palsanto decenio (y no haly, a lo que creo, signos (le vartiación sustancial al menos por el momento) es, en mi opinión, la extensa encuesta realizada por los editores de la revista Nen literary Itistory bajo la divisa «literaty Theory in the University: $\Lambda$ Survey» entre una cuarentena de selectos profesores, investigaddores y estudiantes graduados de algunals de lats mejores Universidades de los Fistados Unidos, Gran Bretaña, Canadí. Alemania, Polonial, Rumanía y Yugoeslavial (Valrios antores, 1983).

l.as preguntas entonces fommlatlas fucron tres: sobre las funciones y objetives de lat Teoría literartia hoy en día: sobre las repercusiones prácticas que la teoría había cenido en la investigación, docencia y. en su caso. aprendizaje de los cucuestados: y finalmente, qué efectos positivos y sobre codo negativos se le podrían alribuir en el contexto de la enscinanza superior. Entre las respuestas dadas habria muchos elementos due comentar, pero sólo conslatare la ratifieación que en ellas he encontrado de concepciones (fue comparto como las de la ("iencia literaria como un área interdisciplinar, urgida por la exigencia de su aplicabilidad a la docencia y el análisis de los textos. necesitadla de la máxima coherencia y simplicidad en sus planteanientos como recharo dél narcisismo teorético y la cutapelia metalinguística cue tanto ha perjudicado su credibilidad. Pero si una de esals concepeiones destaca entre las demás por su resteración por parte de la glan mayoría de les preguntadlos, ésa es sim clucla el pharalismo.

Desde mi visión personal, dicho desideranum del pluralismo posestructuralistal comprende no uno, sino tres compromisos que palso a exponer con brevedad.

I lace ya más de veinticinco años. René Weilek (19)(3.3. 24) escribía: «Debemos recomenzar la larea de construir una teoria literaria. un sistema de principios. una teoría de valores que, necesartiamente, dé lugar a la crítica de las obras de arte en sí y constantemente recurra al auxilio de la historia lieratia. Pero las tres disciplinals son y seguirán siendo distintas».

Se (lelimita así, sucinta y certeramente, el contorme de esals tres grandes ramals de los estudios literarios a las cue cumple añadir una cuarla, la I.iteratura comparada sobre la yue el propio Wellek liene asimismo penetrantes páginass en su obra de 1963. pero se subraya a la ve\% la íntima comunicación que existe entre ellas. Todals comparten un mismo objeto material, los textos considerados literarios, que presentat a la vez dos facetas distintas, la reórica constiluida por el sistema de aspectos constantes y especílicos de dichos textos artísticos, justificativos de su condición de hales, y la empirica. Fsta última, concretada en el conjunto heterogéneo de las obras de arte verbal en sí, puede ser abordada desde tres perspectivas dife- 


\section{DARÍ() VII.L.ANUF,VA}

rentes, la sincrónica, la diacrónica y la comparativa, gue dan lugar. respectivamente, a la Crítica, la Historia literaria y la literatema comparada.

Pluralismo significa a estos efectos el convencimiento absoluto de que entre estas cuatro disciplinas en las que se articulan los estudios literarios existe una dependencia lotal, hasta el extremo de que ninguna pueda alcanzar un cabal desarrollo sin el concurso de las otras,

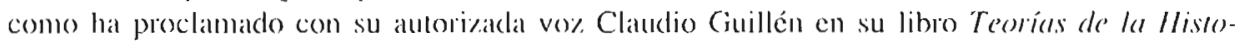
ria literenta (1989). Fin este sentide, el proceso del conocimiento en nuestra área no se diferencia apenas del que. por ejemplo, F. Coseriu proponía para la lingizística, la cual por la naturaleza misma de su objeto debe moverse constantemente entre los dos polos opuestos de lo concreto y de lo abstracto: «Subir de la comprobación emprírica de los fenónenos concrelos a la abstracción de formas ideales y sistemáticas, y volver luego a los fenómenos concretos enriguecida por los conocimientos generales adquiridos en la operación abstractiva. I.o importante es que no se conforme con la abstracción y no se fuecle en ella, porepue la íntima comprensión de la realidad del lenguaje podrá alcanzarse solo en ese tereer momento de vucla a lo concreto. Ll linguiista. si se nos permite una imagen, debe ser al mismo tiempo botánico y jardinero» (Coseriu, 1967, p. 16-17).

I.o dicho impone no sólo la obliganoricuad de fundamental empíricamente toda tcoría, sino algo que estimo aúm más importante si cabe: la necesidad perentoria de que nunca perdamos contacto con la realidad de los textos, en donde está el contraste para determinar la funcionalidad de las propuestas de la teoría literaria, sin el cual es fácil que éstas deriven peligrosamente y bien reciente está el cjemplo de la deconstrucción- hacia lo que Harry Levin denunciaba como pura logomanaia, una especje de ociosa metafísica literaria. Ignalmente estoy convencido, no obstante, de que sin un sólido fundamento teórico la Crítica y la Historia literarias pierden rodo rigor, y de gue la perspectiva comparatista of rece inestimables servicios lanto a estas últimas disciplinas como a la propia Teoría cle la literatura, ya cque la presencia de las constamtes o leyes gencrales de la literariedad en obras insertas en tradiciones parcial o totalmente independientes da razón o la niega a las puras formulaciones teóricas.

Amén de esta cuádruple colaboración interelisciplinar, el segundo compromiso pluralista de los tres a que nos obligaba la situación posestructuralista de muestros estudios aconseja un razonable eclecticismo o armonización entre los diferentes métolos y escuelas que nos ofrecen su instrumental teórico-crílico para el desentrañamiento del fenómeno literario, eclecticismo arraigado en una doble actitud de modestia intelectual, por la que nos convenceremos de antemano (le que cualguier hallargo metodológico, por sumamente innovador (que parezca, nunca lo será lanto tras veinticinco siglos de pensamiento metaliterario, y a lo más a lo que llegará será a abordal problemas de siempre desde matices parcialmente nuevos. Así, tan sólo albergaremos la discrela esperanza de llevar nuestros análisis y propucstas un poco más lejos, o por mejor rumbo que nuestros predecesores.

Scrán exigencias irrenunciables, lambién, la claridad expresiva, la precisión en el empleo del melalenguaje y un radical antibizantinismo (que no son precisamente virtudes sle la crítica más pretenciosa, alejada del rigor filológico y entregada al juego irresponsable de sucesivas alianzas con los métodos más nuevos, por lo general importados de otras provincias no literarias de la Ciencia y la Filosolía. «l a búsqueda de la verdad solo es posible si hablamos sencilla y claramente, evitando complicaciones y tecnicismos innecesarios», alïma Popper $(1972,51)$ a propósito de su actividad filosófica, pero sus palabras son plenamente de recibo también para nosotros: "Para mí, buscar la sencillez y lucidez es un deber moral de todos los 


\section{PLURALISMO CRIITICO Y RECEPCIÓN LITERARIA}

intelectuales: la falta de claridad es un pecado y la presunción un crimen». Esta última cita, que se podría resumir en una conocida máxima orteguiana, señala uno de los caminos a seguir por la crítica pluralista. Precisamente una de las frases de la conferencia de Leo Spitzer «Desarrollo (le un método» pronunciada en Roma hacia 1960) poco antes de su muerte proclamaba que «el buen sentido cs la única guía válicla del crítico» (1980, 58), cn convergencia con la afirmación de Popper de que "toda ciencia y toda filosofía son sentido común ilustra(los» $(1972,42)$ y muy en la línca del $\%$. S. Liliot, para quien cl único método válido en crítica literaria era la inteligencia, y cuyo confeso pluralismo le llevaba a reclamarse miembro, a estos cfectos, de la cue él denominaba uescuela del limón exprimido».

El tercer compromiso a que nos obliga el pluralismo posestructuralista compete a las tres perspectivas o ángulos de enfoque primordiales desde las que cabe abordar el estudio de las obras de arte verbal entendidas como procesos comunicativos y merecerá por mi parte una atención demorada en este último tranco ya de las presentes páginas.

Fin efecto, la vigente sendencia hacia el estudio de la Literatura desde su actualización, que inspira la "Rezeptionsästhetik» alemana y en los Estados Unidos el «Reader-response Criticism», parece explicarse cabalmente de acuerdo con una secuencia histórica que a lo largo de los últimos ciento cincuenta años la visto cómo a un interés fundamentalmente genetista, que lo centraba todo en el autor y su contexto de los que la obra cra simple resultado, sucedía luego, cuando tal actitud metodológica hizo crisis, el traslado del centro de atención investigatiora al mensaje propiamente dicho, para gue tras la fecunda ctapa formalista y estrucluralista se suscite, por fin, la consideración de la Literatura desde el último elemento de la estructura comunicativa cue la sustenta: el receptor o lector.

Ilay una carta de Turguenev, doblemente valiosa en cuanto revela una experiencia directa del fenómeno por parte de un escritor, que ilustrat a la perfeceión el modo de hacer del positivismo historicista del pasado siglo. Fin ella el novelista ruso se cueja de que sus amigos Sainte-Beuve e Hyppolite Taine no prestasen suficiente atención al arte, a la obra en sí misma--«l'ocuvre en soi», expresión de Flaubert-, a la composición, al estilo, en una palabra -añadía- "al lo que crea la Belle\%a». Y es cierto que incluso en Gustave Lanson, cuyo método en modo alguno es reductible a esta caricatura (jue me attrevo a fabular, a veces la activiclad de los historicislas se asemeja a la de un doctor que recibiese al paciente y durante largas horas elaborase con él una cumplicla historia clínica, con cletalle de toclos los datos personales, familiares y analíticos imaginables, para concluir cerrando el expediente, archivándolo y despidiendo al enfermo que sin duda le preguntaría: «Pero en definitiva, i, (ué es lo que tengo doctor? ¿(iripe o cáncer de colon?». A lo que el diligente galeno daría la callada por respuestia.

El estudio intrínseco de la Litcratura, radicalmente instaturado por el formalismo ruso y otros lormalismos concomitantes, rompe con esa tautología (lel «tel arbre, tel fruit», y se prolonga hasta la Poética estructuralista de sóliclas bases linguísticas. Pero un nuevo agotamiento del paradigma llevará a la asumpción del principio implícito col aquella conocida pregunta de Maurice Blanchot: "Qu'est-ce qu'un livre qu' on ne lit pas. Quelgue chose qui n'est pas encore écrit». Se consagra así el reinado de la recepción en lós estudios literarios, parodiado por Terry Fagleton $(1982,449)$ mediante el anuncio de cuál es la revolucionaria consigna del RI.M, «Readers I,iberation Movement»: «The authors need us; we don't need the authors!».

Fintre nosotros no faltan acreditadas voces que han denunciado ya los excesos de esta "corriente de moda», fruto de la «cuforia coyuntural» que la «novedosa propaganda de la estética de la recepción» ha extendido por docpuier, hasta el extremo de alcanzar a ilustres se- 


\section{DARÍO VILLANULVA}

miólogos como Umberto Leco, ucontagiado también por la oleada de achalizaciones de moda sobre el papel del receptor» (Giarcía Berrio, 1989), 217). Desde tal posición de críticar esta corriente se considera muestra extremal del uescepticismo posestructuralista y pragmático». al que se achaca el resultado indescable (también para mí) de relativizar el significado literario no hasta el extremo de negarto de lorma absoluta, como propugna la deconstrucción, sino en cuanto producto esencial del texto objetivantente intencionado por el autor (Carcía Berrio, $1989,216,219)$.

Cumple, no obstante, romper una lanza a favor de la terría de la recepción literaria, sobre todo cuando, como es mi caso, no dudé en denuncialr la ambigüedad conceptual de lass propuestas más conocidas de Wolgang lser en sus dos libros Der Implizite Leeser (1982) y Der Akt des leesens (1976) (Villanueva, 1984) e intentall resolverla, al menos en parte. Y lo haré desde una doble perspectival: negande primero el carrácter de novedosa moda (ue el estudio de la literatura desde el lector adquiere cuando se le considera hijo predilecto del posestructualismo, y alirmando después su condición integradora, no excluyente, de las otras dos perspectivas del autor y el texto antes mencionadas. Fis decir, proclamando su virtualidad pluralista.

Fil principio de la recepción está ya en la taíz del interés de la Sofístical hacia el ante de la palabra, así como en el cle Platón, obsesionado, más que por la poesía en sí, por sus elecetos, y en la propia Rétórica y Pósica de Aristóteles. Agunélla, como técnica pala la óptima elaboración y conuciación de los discursos, tiene siempre en cuenta la exigencia de su efectiviclad en el auditorio, y en la Poética conceptos fundanentales como el de la canarsis o la verosimilitud entendida en forma del acomoslo a lo que el público esté dispuesto a aceptar como cierto y posible y no lo que realmente lo es («Se debe preferir to imposible verosímil a lo posible increíble», 60a 26-27) desaniman cualquier ingenual pretensión de descubrit, al estas alturas, nuevos Mediterráneos.

La gue sí es cierta es la renovada vigencia de estos presupuestos desde finales de los años sesenta, sin cue falte entonces el reconocimicnto por parte de sus nuevos defensores de las formulaciones primigenias de aquellos. Así por ejemplo Wayne (. Booth (19)74. xiv) confiesa que hara con la ironía lo que Longino habia hecho ya con otra cualidad litcrarial. lo sublime, porque ambas pueden residir tanto en el atutor como en la obra como en el receptor.

Ya ha sido muy oportunamente destacado por Carmen Bobes Naves (1988. 40.3 y ss.) lo impreciso de la atribución de los excesos indeseables de la Listética de la recepción. el Deconstructivismo y la Pótica de lo Imaginario al irracionalismo redivivo en nuestra postmodernidad, cuando hay que remontarse a Fichte y a su teoríi idealista del conocimiento para hallar las raíces del proceso positivo que ha culminado con la llamada "hora del lector». Desde el momento en que el arte pasal a ser comprendido como una pura creación subjetiva. en la que el Yo del artista no se somete a las delerminaciones de la objelividard del mundo real ni a las convenciones estéticas heredadas de la tradición. el papel del receptor se vuelve más arduo, pues carrece de pautas parai el conocimiento y la valoración de la obra, pero precisamente por ello más activo y esencial, yal (que en torno al objeto estético se trenzal un decisivo flujo de intersubjetividades: la del creador y lia de sus receptores.

Fn esa frontera del idealismo alemán del XVIII y no en Georg Galamer (Vidl. Giarcía Berrio, 1989, 221 y 24.3) o, menos aún, en una moda posterior y pasajera se encuentra la clave del «cambio que lleva de la tadición a la modemidad» (Bobes Naves, 1988, p. 467) y" descle entonces se puede contar con otro antecedente claro de la estética de la recepción, que 


\section{PI.URALISNIO CRÍTICOO Y RLC:EPCIÓN IITTERARIA}

no seria por lo lanto consecuencia del agotamiento del paradigmal estructuralistat, sino muy anterior a él.

lise hito de obligado recuerdo. tan oportunamente aducido por María del Carmen Bobes Naves, se compadece a la perfeceión con la naturaleza del método fenomenológico de Eelmund Husserl, actualización moderna de la «epojé» de los escépticos y la duda cantesiana, (fue mediante la suspensión de exlo juicio puede atenerse a lo daclo describiéndolo tal y como se presenta. No laty, pues, contenidos de conciencia, sino únicamente fenómenos.

El principio fenomenológico de la experiencia en la que se basa todo conocimiento, for-

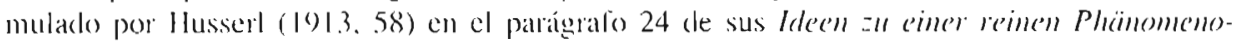
logic und phänomemologische'n Philosophlié. Maducidas al español en 1943 por José (jacos y al francés por Panl Ricocur en 1950, viene a justificar una evidencia: que lá realiclad de la literatura se fundamenta en nuestra aproximación a ella como lectores.

ris perfectamente legítimo, a la hora de intentar una refutación de la perspectiva teóricoliteraria de la recepción por el énfasis que esta pone en la capacidad donadora de semlido que se le atribuye al lecter la «semiosis ilimitadia-, afimar (pue de ello se sigue la "entele(yuia de un lector sin texto» (Carcía Berrio, 1989, 213). Mals cabe también (arle por comple10 la vuelta al argumento, aduciendo la aporía de un texto ontológicamente realizado en plenitud sin su lector, fundamentada en ese "platonismo latente» denunciado por María del (armen Bobes Naves (1985, p. 8) en su arlículo "l.a Regena descle la estélical de la recepción». ¿De qué hablamos cuando lo hacemos sobre una obra que no hemos leído? i() de otra como, por ejemplo, la Essinge de Polomeo, hijo de Itefestión, que Suidas leyó pero se ha perdide"? ¿Se puede, en definitiva, tratar de los textos literarios de otra forma yue no sca desde la experiencia de la lectura? Y no es recomendable en modo alguno el ejemplo aportado por esos críticos de oficio que tras largos años de profesión pueden reseñar un libro sin haberlo leído, solo con haberlo tenido entre las manos...

Dejo al mangen una constatación muy interesante: la de que entre los lundaclores de la Fenomenología, desde Hegel a Husserl, hay que contar a Charles S. Peirce, cuya Semiótica se fumdamenta en la que él denomimaba "fincroscopia», disciplina yue se abstiene de loda especulación, limilándose a describir las apariencias immediatas con exactitud máxima. Nada extraño hay, por ello, en que los semiólogos más rigurosos hayan aceptado sin reservas la teoría de la recepeión literaria que viene directamente de la Fenomenología.

También en los origenes del formalismo ruso aparece la fenomenología. Las ansias de renovación científica de los jóvenes del Círculo lingüístico de Moscú encontraron luente inagotable de inspiración en las logische Unersur/umgen, y, en general, en todo el pensamiento de Husserl, divulgado entre ellos por un discípulo suyo, Gustav Sper, cue allí profesaba. Tanto es así (que Victor Erlich (196.5: 89) consideraba esta inlluencia, junto a la lascinación por los hallazgos de la vanguardia litcraria rusa de entonces, como los síntomas principales del fermento intelectual del que nació la escucla formalista constituida en tomo a acpuel Córculo y la Opoiar de San Petersburgo. Ambas incitaciones convergen, por ejemplo, en el arlículo de Roman Jakobson sobre Xlebnikov, discuticlo ante un selecto grupo de estudiantes y poetas moscovitas contre los que se encontraba Maiakovsky, y que consistía ni más ni menos (ue en un examen del verso futurista ruso a la luz de los conceptos de llusserl y de Saussure (Cfi. R. Jakobson, 1973). Precisamente a parlir (le la marcha de Jakobson, en 1920, el Círeulo de Moscú decate, hasta su definitiva escisión en dos grupos de tendencia, respectivamente, marxistal $y$ husscrliania. 


\section{DARÍ() VII.I.ANUEVA}

La tradición de los formalistas rusos se prolonga, como es bien sabido, en Checoestovaquia a través del Círculo lingüístico de Praga (1926-1948) al que se incorporará el propio Jakobson y Nicolai Trubetzkoy. Entre los investigadores autóctonos que forman en este nuevo círculo, Mukařovský se inspira, asimismo, abicrlamente en Husserl. Su concepción tcórica de la Literatura en el marco de una más amplia teoría de la comunicación parte del supuesto de (que la obra de arte verbal no se puede reducir a su aspecto material - lo que él denomina el «artefacto»-, sino que debe ser considerada en cuanto objeto estético, esto es, la actualización (lel artefacto en la consciencia del receptor (CCr. Jan Mukařovský, 1977). en términos extraordinariamente similares a los de la ontología de la I iteratura del discípulo polace (le Husserl Roman Ingaiden.

Posteriormente, Felix Vollicka desarrollará estas ideals en el terreno específico de la flistoria literaria, y su vo\% llega hasta la Universidad de Constanza, como también la de los mismos formalistas rusos, en especial Kïchenbaum, Tynianov, Sklovsky y Jakobson (Cfr. II. R. Jauss, 1970, 158-195).

Simultáneamente a la actividad del Círculo checo, y sin entrar en contacto con él, el mencionado Ingarden llevaba adelante el más ambicioso intento no siempre coronado con el éxito- le aplicar la filosolía de su macstro de (iottinga y de Friburgo a la I iteratura, para resolver fenomenológicamente las dos cuestiones funclamentales que nos plantea: la de la ontología de la obra de arte literaria, a la que dedicá su primera obra, publicada inicialmente en alemán (R. Ingarden, 1931), y la epistemológica referente a cuáles son los caminos por los que accelemos a su conocimiento y aprehensión. Fsto último se aborda en un tratado postcrior, aparecido en polaco en 19.37 y traducido con notable retraso al alemán y al inglés (R. Ingarden, 1968).

Para Ingarden, la obra de arte literaria tienc su origen en actos creativos de la consciencia intencional por parte del autor. Su base óntica reside en una fundamentación física - papel impreso o manuscrito, banda magnética, disco de ordienador, etc. - que permite su existencia prolongada a través del ticmpo, y su estructura interna es pluriestratificada, en la que operan un estrato de los sonidos y las formaciones verbales; otro de las unidaes semánticas; un tercero de las objetividades representadas, correlatos intencionales de las frases; y, por último, el estrato de los aspecos escuematizados bajo los (fue esas objetividades aparecen. La intención artística crea una sólida trabazón entre todos ellos, justificando así la armonía polifónica de la obra, y gracias en especial a su doble estrato lingüístico (fónico y senántico), la obra es intersubjetivamente accesible y reproducible, de forma (jue se convierte en un objeto intencional intersubjetivo que se refiere a una comunidad abierta, espacial y temporalmente, de lectores. Precisamente por ello la obra de arte literaria no es un mero fenómeno psicológico, pues trasciende todas las experiencias de la consciencia, tanto las del autor como las del lector.

Pero la obra de arte literaria cleja muchos clementos (le su propia constitución ontológica en estado potencial, pues es la suya una entidad fundamentalmente esquemática. I a actualización activa de la misma pos parte del lector subsana esas lagunas de indeterminación («unbestimmtheitsstellen») o clementos latentes, y si es realizada con una actitud estética positiva, convierte el objeto artístico que la obra es en un objeto estético pleno.

En este orden de cosas, cada uno de los estratos que ontológicamente componen la obra reclama (liferentes actualizaciones, pero, sin (letrimento de la concretización de todo el conjunto como unidad, destaca en especial el proceso de donación de sentido que el lector cmprende a partir de las unidades semánticas y de las objetividades representadas, tarea en la 


\section{PLURALISMO CRÍTICO Y RECEPCIÓN LITERARIA}

que el esquematismo del que hablábamos exige la aportación de aquellos elcmentos ausentes $o$ indetcrminados sin los cuales la obra no alcanza, cmpero, plena existencia.

Ello deja abierto un margen de variabilidad entre los valores artísticos inherentes a la obra en sí y los valores estéticos alcanzados en la concretización o concretizaciones cjue la provean de su total plenitud ontológica. La diferencia fundamental cntre una obra de arte literaria y sus actualizaciones es que en éstas se concretan los elementos potenciales y se complementan las «lagunas» o vacíos de indeterminación de aquélla. Los valores artísticos, pertenecientes a los diversos estratos, son algunos de esos elementos potenciales, y su productividad estética depende en gran medida del sistema de relaciones que se establezcan entre cllos, es decir, la armonía cualitativa equiparable a la gelstalt, o, en otra terminología, a la estructura.

A lo largo de este completo programa de investigación fenomenológica Ingarden se muestra muy próximo a los formalistas - con los que no sin cmbargo no estaba en contac10- por su antipsicologismo, su énfasis inmanentista en conceder primacía, en el marco de su concepción auténticamente estructural de la obra de arte literaria, a los estratos en esencia verbales de la misma, y, claro está, por la trascendencia que otorga al proceso de lectura o actualización en la definitiva constitución ontológica de aquélla. Con ello está scntando la bases para el ulterior desarrollo de las diversas tendencias - historicista, sociológica, estilística, semiológica, psicoanalítica, hermenéutica, etc.- de la estética de la recepción actual.

Pero esta huella de una fenomenología que inspira a la ve\% a la ciencia literaria formalista y a la de oricntación pragmática o incluso cmpiricista - huella resumible en afirmaciones como la de M. Riffaterre $(1979,9)$ : «Le phénomène litterairc n’est pas seulement lc texte, mais aussi son lecteur et l'ensemble des réactions possibles du lecteur du texte -énoncé et énoncialion»-, alcan\%a además amplia difusión a ambos lados del Atlántico desde 1949 gracias a un manual ya clásico de Tcoría literaria, escrito por un checo de nacimiento y de formación, lucgo emigrado a los Estados Unidos, y un nortcamericano - René Wellek y Austin Warren (1953) - que fue traducido al castellano antes que a cualquicr otra lengua por decisión del maestro de la Filología española Dámaso Alonso. Cuando, al prologarlo, manifestaba su plena coincidencia de puntos de vista con los autores, «tanto - escribe- que yo) podría asentir sin la menor violencia a las tesis fundamentales de la presentc obra", en cllo iba el reconocimiento de cse eclecticismo positivo que desde una línea de pensamiento vertebral en este caso, lenomenología más formalismo- se abre, impregnado del espíritu humanista consustancial a la tarea filológica, a todas las incitaciones científicas c intelectuales.

Quede para otra ocasión al análisis en paralclo de la tcoría ingardiniana de los diferentes tipos de experiencia litcraria que desarrolla en Vom Erkennen des literarischen Kunstwerks y los sucesivos capítulos que Dámaso Alonso dedica en Poesía española al "primer conocimiento de la obra poética: el del lector», el scgundo conocimiento (de la crítica) y al tercero propiciado por la tcoría literaria (1950). Amado Alonso, por su parte, trabajaba en una Pó́tica que lo prematuro de su muerte frustró cuando, scgún testimonio que he podido escuchar de algunos de sus más directos colegas, aconsejaba a todos la lectura de Husserl c Ingarden. Sin citarlos, curiosamente, a ellos remite la propia fraseología de su «Carta a Alfonso Reyes sobre la estilística» cuando leemos: «Significación es la referencia intencional al objcto (un acto lógico)» (A. Alonso, 1955, p. 79). El mismo Alionso Reycs no era menos sensible a cstas influencias, que le inducen a emplear desde 1933 el término «fenomenografía» (Reyes, $1942,73, \mathrm{n} .1$ ) en un libro titulado precisamente La experiencia literaria. De la pervivencia entre nosotros de esta constante fenomenológica, en la que se integran los rextos teóricos de 


\section{DARÍO VII.I.ANIJFVA}

Irancisco Ayala, da buena cuenta el hecho de gue en los coloquios sobre historial y estructura de la obra literaria celebrades en maro de 1967 en el Consejo. Superior de Investigaciones ('ientíficals, meses antes del famoso discurso académico de Hans Robert Jauss en Constanza titulado "la historia litcraria como cécsafío al la ciencia litcrarial», Ricardo Senabre (1971: 21) dedicara toda su intervención a reivindicar, con convincentes argumentos y pruebas. en qué medida el público lector. "ese factor huidizo y habilualmente desestimado ha influido siempre» en aquella estructura, aspectos (ue luego ha desarrollado ampliamente en un libro de 1986. Poco despućs Fernando Lázanro Carreter $(1976: 43)$ en una lección magistral titulada "i.Qué es la literatura"» calificaba de (lecisivo el. papel (lel lector. en cuanto a él corresponde la iniciativa de actualizar la obra, "creada como mera propuesta por el autor. Lis allí. por tan10. donde esa obra adquiere, si lo adcpuicre. su valor estético».

No hay, pues, ruptura ni contradicción posibles entre la consideración de la literatura desde la perspectiva del mensaje en sí y desde su acogida o recepción. Vil texto mantiene su existencial latente a lat espera de que su destinatario. mediante el acto de lecrlo, lo convierti en un objeto estético en plenitud. Pero aungue esta última perspectiva sea inexcusablemente la de rodos nosorros, pues no de orre modo o desde orro ángulo o posición podemos acceder a la aprehensión de la obra de arte literaria, lo cierto es que en un principio fue el verbo, por mucho que (lemore su llegadda al lector. Nadla más Iejos de nuestrat idea de la recepción literaria que la siguiente denuncia de A. García Berrio: "l a pretendicla apertura del texto como resultado de la libre interpretación no acaba siendo un modo de cooperar del lector con la signilicación, sino una manera de destruir el texto, de relegarlo a la innecesartia función de un pretexto superfluo, de una presencia falaz gue, si no llegal a ser redundante es porque sobrevive en realidad como un puro simulacro sin capacidad de referencia» (1989), 216).

No será paradójico sostener, incluso, que precisamente la apertura del inmanentismo formalista hacia cl lector como elemento fundimental de callat a la plena realización del mensaje como proyecio comunicativo lleva emparejada una recuperación homóloga de la figura del autor, cuyal larga y solitaria travesía del desierto todo parece inclicar que está tocando a su lin en el territorio de la Ciencia literaria. Véase. por ejemplo. la excelente ponencia de Fernando I. ázaro Carreter (I9)0) tituladla «Ll

poema lírico como signo».

No (puiero concluir sin exponer, finalmente, otro argumento esta ve\% de índole práctical, y creo que lleno de interés- a lavor de los electos benéficos que la aclitud (mejor que método. pues al fin y al cabo todos o casi todos han acabado por hacerla suya) de la recepción puede cjercer. Se trata de propiciar a través de clla estímulos de cooperación por parte de los alumnos en el proceso docente. Así lo sugería Sicgfried J. Schmidt (1979, 565): la acetitud pasiva del estudiante de Litcratura debe ser combatida, cuando se da, precisamente en virtud de las funciones activals como receptor y "postprocesador" que el LI'TERATURSSYSTEM descrito por la "Empirische Literaturwissenschaft» le confiere.

En similares términos Jonathan Culler $(1981,219)$ aplaude las implicaciones didácticas de la estilística "afectiva» de Stanley F. Fish (1980), y Norman lolland, inspirador de la "Escuela de Búllalo» que ha sabielo armonizar la crítica piscoanalítical con la perspectiva de la recepción, daba la siguiente respuesta a la pregunta de Now Lirerary /listory sobre la influencia de la Teoría literaria sobre su ejercicio profesoral: "l used to think of myself and my students as objectively analyzing texts. Now I acknowledge and emphasize the personal response of student, teacher, and critic. I cncourage the conscious use of One's self, One's identity, really, as a sensing instrument» (Varios autores, 1983: 429). Sin que ello signifique, 
por supuesto, la arbitrariedad absoluta, e impiclat la clenuncia en el aula de lecturas incomplelas, incorrectas o. por qué no decirlo, aberrantes. Lil patrón que las mide y revela es el propio texto, claro está. Pero el texto... leido y contrastado en sus lecturas, tal y como se ha venido haciendo académicamente desde antes de la aparición de la Iniversidad medieval. George Steiner, por su parte, ahíto de tantas excentricidades y galimatías como la crítical más sofïsticarda practical recalcitrantemente, recordaba en un famoso artículo de 1979 que "lo (jue necesitamos son lugares; por ejemplo, ma mesa con mas sillas alrededor donde podamos volver a aprencler al leer, a leer juntoss (Steiner, 199(), 130).

Precisamente en un recientísimo capítulo de una enciclopedia Terence Mawkes (Varios autores, 199(). p). 926 y sig.) ha estudiado el papel de la Universidad anglosajona en la instilucionalización de la literatura y mos ha recordaclo cómo la uclose reasling" del New Criticism no éa más que la práctica acalémica de la kectura tutorizada por los profesores. del mismo modo que en Cambridge I. A. Richards llevaba adelante desde los años veinte un programa similar. pues no en otra cosa consiste su «Practical Criticism». Paul de Man, uno de los más lácidos deconstructivistas de Yale, ha recordaclo su experiencia de cste método aplicado por el profesor Brower en Harvard durante los años cincuenta en un artículo memorable publicado en The Times lirerer. Supplement en 1982. Fi "mero acto de leer" escribe de Man ela capaz de Iranslormar la actitud y competencia de los estudiantes en kerminos inclescables por quienes veían en la enseñam\%a de la literatura «un sustituto de la enseñan\%a de la teología, la ética, la psicología o la historia intelectual», de lo sue deduce cue aquella experiencia docente y la posterior consolidación de la teoría literaria en los currículos acaclémicos (que ahora estamos viviendo en lespaña). pese a las resistencias (que el mismo Paul de Man denunció, eran procesos debidos a una raíz combin: "una vuclta a la filología, a un examen de la estructura del lenguaje previa a la del significado que produces (de Man, 1990, 44).

I a actitud filológica se diferencia de la bibliofílica poreque el amor a las palabras hechas libro que inspira a ambas demanda de la primera la consumación de ese encuentro revelador y activo que propicia la lectura. No nos quecla sinos suscribir otra alimación del autor (e Blindmess and Insighll: "mi punto de partida (...) no es filosólico sino básicamente filológico, y. por ese motivo, didáctico, orientado hacia el texto. Por lo tanto, tengo tendencia a investir a los textos de una autoridad inherente que es más fuerte, creo yo, que la que Derrida está (lispuesto a datles» $(1990,18(1)$.

\section{Referencias bibliográficas}

ALONSO, Amado

195.5 Materia y forma en poseśa. Madrid, Gredos (tercera edición, 1977).

ALONSO, Dámaso

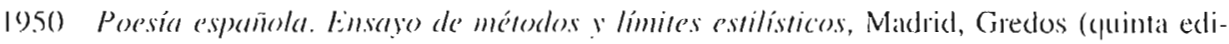
ción, 1966).

AUI.I.ON DE: HARO, Peclro (compilaklor)

1984 Introducción a la critica literaria actucel. Madrid,Playor.

BOBFS NAVES, María del Carmen

197.5 Cirameitricu de "Cémtico" (Análisis semiológico). Barcelona, Planela/Universidade de Santiago de Compostela. 


\section{DARÍO VILLANUEVA}

198.5 «La Regenta desde la estética de la recepción», Letras de Deusto, 32.

1988 «La póetica al día», Anales de Literatura española, 6.

BOOTH, Wayne C.

1974 A Rhetoric of Irony, Chicago/l ondres, The University of Chicago Press.

1979 Critical Understanding. The Powers and Limits of Pluralism. Chicago/Londres, The University of Chicago Press.

1986 «Pluralism in Classroom», Critical Inquiry, 12.

COSERIU, Eugenio

1967 Teoría del Lenguaje y Lingüissica general, Madrid, Gredos.

CULLER, Jonathan

1981 The Pursuit of Signs. Semiotics, Literature, Deconstruction, Ithaca, Cornell University Press.

DE MAN, Paul

1990 La resistencia a la teoría, Madrid, Visor.

\section{EAGLETON, Terry}

1982 "The Revolt of the Reader", New Literary Mistory, XIII, 3.

ERLICH, Víctor

196.5 Russian Formalism. History-Doctrine, The Hague, Mouton. Versión española de J. Cabanes, El formalismo ruso. Historia-Doctrina, Barcelona, Seix-Barral, 1974.

FEYERABEND, Paul K.

1986 Realism, Rationalism and Scientific Method. Philosophical Papers. Vol I, Cambridge, Cambridge University Press.

GADAMER, Hans Gcorg

1965 Wahrheit und Methode, 'Tübingen, J. C. B. Mohr. Versión española de Ana Agud Aparicio y Rafacl de Agapito, Verdad y método. Fundamentos de una hermenéutica filosófica, Salamanca, Sígueme, 1977.

GARCÍA BERRIO, Antonio

1978 «Lingǘstica del texto y texto lírico (La tradición textual como contexto)», Revista española de lingiuística, 8, 1.

1989) Teoría de la literatura (La construcción del significado poético, Madrid, Cátedra.

GARRIDO GALLARDO, Miguel Ángel

1982 Estudios de Semiótica literaria, Madrid, C. S. I. C.

GUILLÉN, Claudio

1989 Teorías de la historia litereria, Madrid, Espasa-Calpe.

HASSAN, Ihab

1986 «Pluralism in Posimodern Perspective», Critical Inquiry, 12, pp. 503-520.

HENDRICKS, W. ().

1976 Semiología del discurrso literario, Madrid, Cátedra.

HJEI,MSLEV, Luis

1969 Prolegómenos a una teoría del lenguaje, Madrid, Gredos.

HAWKING, Stephen

1988 Historia del tiempo, Barcelona, Crítica. 


\section{PLURALISMO CRÍTICO Y RECEPCIÓN LITLRARIA}

\section{HUSSERL, Fdmund}

1913 Ideas relativas a una fenomenología pura y una filosofía fenomenológica, traducción de José Gaos, México-Madrid, F. C. E., 1949.

INGARDEN, Roman

1931 Das literarische Kunstwerk, tercera edición, 1965. Tubinga, Max Niemeyer Verlag.

1968 Vom Erkennen des Literarischen Kunsmwerks, Darmstadt, Wissenchafiliche Buschgesellschat.

JAKOBSON, Roman

1973 Questions de Poétique, París, Du Seuil.

JAUSS, Hans Robert

1970 Literaturgeschichte als Provokation, Trankfurt am Main, Suhrkamp Verlag.

I.ÁZARO CARRETER, Fcrnando

1976 ¿Qué es la literatura?. Madrid, U. I. M. P.

1980 Essudios de Lingüissicu, Barcelona, Crítica.

1990 De poética yo poéticas, Madrid, Cátedra.

MUKǍ̆OVSKÝ, Jan

1977 Escritos de Estética y Semiótica del Arte, Barcelona, Gustavo Gili.

POPPER, Karl R.

1963 Conjectures and Refunations. The (Frowth of Scientific Knowledge, I.ondres, Routledgc and Keagan Paul. Traducción al castellano de Néstor Mígue7, Comjeturas y Refuraciones. El desarrollo del conocimiento científico, Barcelona-Buenos Aires, Paidós, 1983, tercera ed.

1972 Objective Knowledge, Oxford, The Clarendon Press. Traducción de Carlos Solís Santos, Conocimiento objerivo. Un enforme evolucionista, Madrid, Tecnos, 1974, 1982.

REYES, Alfonso

1942 I a experiencia literaria, tercera edición, México, F. C. F.

RIIFATFRRL, Michacl

1979) La production du texte, París, Du Seuil.

SCIIMIDT, Sicglriel J.

1979 «Lmpirische Literaturwissenschaft as Perspective», Poetics, 8.

1980 Grundriss der Empirischen Literaturwissenschaft. Band I. Der gesellschafilliche Handlungsbereich Literalur, Braunschwei-Wiesbaden, Vieweg und Sohn. Traducción inglesa y revisión por Robert de Beaugrande, Foundations for the Empirical Sundy of Literature. The Components of a Basic Theory, Hamburgo, Helmut Buske Verlag, 1982. Versión española de Francisco Chico Rico, Fundamentos de la ciencia empírica de la Literatura, Madrid, Taurus, 1990.

SENABRE, Ricardo

1971 «El influjo del público en la estructura de la obra literaria», en Varios Autores, Historia y estructura de la obra literaria, Madrid, C. S. I. C., pp. 19-28.

1987 Liseratura y público, Madrid, Paraninfo.

SPIT'ZER, LeO

1980) Estilo y estructura en la literanura española, Barcelona, Crítica. 


\section{DARIO VIILANUI:VA}

SHIINIR. (

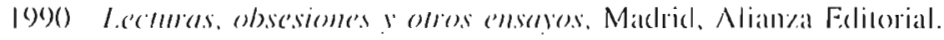

\section{VARIOSS AUTORFS}

198.3 "literary Theory in the University: A Survey", New linerary Ilistory. XIV, 2.

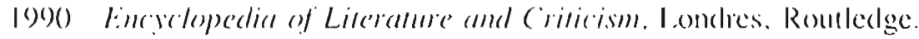

VILLANUI:VA. Darío

1984 "Namalario y lectores implícitos en la evolución formal de la movela picarescan, en L.

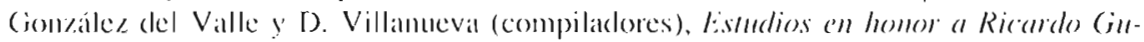
llom. Lincoln, Society of Spanish and Spanish-American Sudies. pp. 34.3-367.

\section{WHI.L.LE.K. René}

196.3 Comere)ts of Criticism. New I laven, Yale Universily Press. Praducción de Folgar Ro-

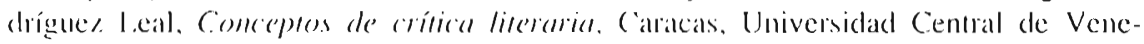
sicla.

WI:I,I.F.K, René, y. WARRLEN, Ausiin

195.3 Teoria lineraria. Madrid. Ciredos. Prólogo (le Dímalso Alomso. 